\title{
Glucagon-like-peptide-1 receptor expression in normal and diseased human thyroid and
} pancreas

\author{
Beatrice Waser, Annika Blank, Eva Karamitopoulou, Aurel Perren and Jean C Reubi \\ ${ }^{1}$ Cell Biology and Experimental Cancer Research, Institute of Pathology, University of Berne, Berne, \\ Switzerland
}

\begin{abstract}
Glucagon-like-peptide-1 (GLP1) analogs may induce thyroid or pancreatic diseases in animals, raising questions about their use in diabetic patients. There is, however, controversy regarding expression of GLP1 receptors (GLP1R) in human normal and diseased thyroid and pancreas. Here, 221 human thyroid and pancreas samples were analyzed for GLP1R immunohistochemistry and compared with quantitative in vitro GLP1R autoradiography. Neither normal nor hyperplastic human thyroids containing parafollicular $C$ cells express GLP1R with either method. Papillary thyroid cancer do not, and medullary thyroid carcinomas rarely express GLP1R. Insulin- and somatostatin-producing cells in the normal pancreas express a high density of GLP1R, whereas acinar cells express them in low amounts. Ductal epithelial cells do not express GLP1R. All benign insulinomas express high densities of GLP1R, whereas malignant insulinomas rarely express them. All ductal pancreatic carcinomas are GLP1R negative, whereas 6/20 PanIN 1/2 and 0/12 PanIN 3 express GLP1R. Therefore, normal thyroid, including normal and hyperplastic $\mathrm{C}$ cells, or papillary thyroid cancer are not targets for GLP1 analogs in humans. Conversely, all pancreatic insulin- and somatostatin-producing cells are physiological GLP1 targets, as well as most acini. As normal ductal epithelial cells or PanIN 3 or ductal pancreatic carcinomas do not express GLP1R, it seems unlikely that GLP1R is related to neoplastic transformation in pancreas. GLP1R-positive medullary thyroid carcinomas and all benign insulinomas are candidates for in vivo GLP1R targeting.
\end{abstract}

Modern Pathology (2015) 28, 391-402; doi:10.1038/modpathol.2014.113; published online 12 September 2014

The receptors for the gut hormone glucagon-likepeptide-1 (GLP1) are physiologically expressed in the endocrine pancreas as well as in very large quantities in specific endocrine tumors such as benign insulinomas. ${ }^{1-3}$ These receptors have increasing clinical importance as, on one hand, they mediate the action of commercially available GLP1 analogs such as exenatide or liraglutide to help treat diabetes patients ${ }^{4-6}$ and, on the other hand, represent the targets for radiolabeled GLP1 or exendin to visualize in vivo insulinoma tumors. ${ }^{7-10}$

In recent years, there have been numerous discussions about potential problems with incretin used for diabetes treatment as it may induce thyroid and/or pancreas pathologies. ${ }^{11-13}$ On one hand, it

Correspondence: Professor JC Reubi, MD, Cell Biology and Experimental Cancer Research, Institute of Pathology, University of Berne, PO Box 62, Murtenstrasse 31, CH-3010 Berne, Switzerland.

E-mail: reubi@pathology.unibe.ch

Received 22 May 2014; revised 4 July 2014; accepted 4 July 2014; published online 12 September 2014 was observed in preclinical animal studies that a significant number of animals developed medullary thyroid carcinomas after long-term treatment with GLP1 analogs. ${ }^{14-16}$ On the other hand, there have been reports suggesting that GLP1 analogs may induce pancreatitis or pancreatic cancers. ${ }^{12,17,18}$ These studies are presently taken very seriously and weighted with regard to the benefits of incretin therapy in diabetes. ${ }^{11,19,20}$ It is important to find a consensus in understanding the molecular mechanisms of the postulated pathologies and to know to which extent the animal data can be extrapolated. ${ }^{11}$

An important prerequisite is to assess exactly the GLP1 receptor (GLP1R) expression in human thyroid and pancreas, as the presence of these receptors in these tissues may be the molecular basis for the deleterious actions of GLP1 analogs. Unfortunately, to date, the various reports on that subject do not provide a clear consensus. ${ }^{11,13}$

There have been early studies by Körner et $a l^{2}$ that found species differences for GLP1R expression in thyroids and lungs, with a much higher expression 
in the thyroid and lungs of rat and mouse than in the corresponding human organs. According to these in vitro receptor autoradiography studies, no GLP1Rs were detected in normal human thyroids, whereas $\mathrm{C}$ cells of normal rat and mice thyroids expressed GLP1R. Moreover, rat thyroids with C-cell hyperplasia as well as two rat medullary thyroid carcinoma tumor models showed a high density of GLP1R in all tested cases. ${ }^{21}$ In humans, however, using the same method, approximately $1 / 3$ of the cases of medullary thyroid carcinomas, but none of the normal thyroids, had GLP1R.,21 These species differences were confirmed by Bjerre-Knudsen et $a l^{15}$ and Boess et al. ${ }^{16}$ A subsequent immunohistochemical study by Gier et $a l^{22}$ in human thyroid tissues, however, has suggested that normal human thyroid and various thyroid pathologies can often express GLP1R. The authors concluded that caution was necessary when treating patients with incretins. Unfortunately, the immunohistochemistry protocol and the antibody used in the mentioned study did not appear to have the necessary specificity for GLP1R immunohistochemistry in human tissues; ${ }^{23}$ a recent paper challenged the specificity of the used antibody, ${ }^{11}$ questioning the validity of the data of this study.

The situation is not much clearer in the pancreas. Although all authors agree for the presence of GLP1R in the pancreatic islets, there are differences at the level of ducts: whereas Körner et $a l^{2}$ Pyke et $a l,{ }^{24}$ and Drucker, ${ }^{11}$ using GLP1R autoradiography, immunohistochemistry, or mRNA analysis, respectively, were unable to detect GLP1R in human ducts, Gier et $a l^{25}$ found such receptors in rat and human pancreatic ducts by immunohistochemistry. In addition, ductal pancreatic cancers were found positive for GLP1R by the same group using immunohistochemistry, ${ }^{25}$ whereas Körner et $a l^{2}$ found no such receptors in pancreatic ductal cancers with receptor autoradiography. Although these discrepancies may be because of the different techniques used to measure the receptor protein, namely autoradiography vs immunohistochemistry, they may also be related to the antibodies used and their level of characterization and validation, as mentioned by Drucker ${ }^{11}$ and Pyke et al. ${ }^{23,24}$

We have therefore evaluated GLP1R in human thyroid and pancreas tissues using an extensively validated GLP1R monoclonal antibody ${ }^{24}$ that we used for immunohistochemistry and western blots and that we compared with results of GLP1R autoradiography in the same tissues. In addition to normal thyroid and pancreas, thyroids with C-cell hyperplasia, chronically inflamed pancreas, and also neoplastic thyroid tissues, namely medullary thyroid carcinomas and papillary thyroid carcinomas, as well as neoplastic pancreas tissues, including pancreatic neuroendocrine tumors, ductal pancreatic carcinomas, and pancreatic intraepithelial neoplasia (PanIN), were tested.

\section{Materials and methods}

\section{Tissues}

A total of 221 formalin-fixed human thyroid and pancreatic tissues (see Tables 1 and 2) were used in this study: normal thyroids $(n=8)$, thyroids with C-cell hyperplasia $(n=8)$, papillary thyroid carcinomas $(n=8)$, sporadic medullary thyroid carcinomas $(n=10)$, familial (MEN 2) medullary thyroid carcinomas $(n=10)$, chronic pancreatitis tissues $(n=9)$, benign insulinomas $(n=31)$, malignant insulinomas $(n=7)$, pancreatic nonfunctioning NET $(n=10)$, ductal pancreatic carcinomas $(n=88)$, PanIN 1/2 $(n=20)$, and PanIN $3(n=12)$. From this series, 19 insulinomas, 57 ductal pancreatic carcinomas, and 26 PanIN were tested solely on tissue microarrays. All above-mentioned tissues were used for GLP1R immunohistochemistry and, in all cases with available fresh-frozen samples, also for autoradiography and western blotting (see Tables 1 and 2). The sample collection conformed to the ethical guidelines of the Institute of Pathology, University of Berne, and was reviewed by the Institutional Review of Board (Kantonale Ethik Kommission).

\section{Immunohistochemistry}

Immunohistochemistry for calcitonin, synaptophysin, insulin, glucagon, somatostatin, and pancreatic polypeptide (PP) was performed on formalin-fixed tissues. The antibodies were purchased as follow: calcitonin (NCL CALp) from Leica (Newcastle, UK); synaptophysin (MO 776) from Leica (Newcastle, UK), insulin (I-2018) from Sigma (Buchs, Switzerland), glucagon from Sigma (Buchs, Switzerland), somatostatin from Dako (Baar, Switzerland), and PP (RP030) from Diagnostic BioSystem (Pleasanton, CA, USA).

\section{GLP1R Immunohistochemistry}

For single-label immunohistochemistry DAB (Diaminobenzidine) staining, paraffin sections were dewaxed and rehydrated to $\mathrm{H}_{2} \mathrm{O}$. Sections were microwave treated for $8 \mathrm{~min}$ at $900 \mathrm{~W}$ and $30 \mathrm{~min}$ at $360 \mathrm{~W}$ in Tris-EDTA buffer, pH 9.0, were allowed to cool for $15 \mathrm{~min}$, rinsed in Tris-buffered saline (TBS), $\mathrm{pH} 7.5$, and blocked in $3 \% \mathrm{H}_{2} \mathrm{O}_{2}$ with $0.15 \mathrm{M} \mathrm{NaN}_{3}$. Slides were incubated overnight with the primary GLP1R monoclonal mouse antibody $7 \mu \mathrm{g} / \mathrm{ml}$ (MAb 3F52; provided by Novo Nordisk, Copenhagen, Denmark) diluted in TBS containing 1\% casein, $5 \%$ normal goat serum, and $0.1 \% \mathrm{NaN}_{3}$. After a wash in TBS for $10 \mathrm{~min}$, slides were incubated for 45 min in Flex + Linker mouse (Dako) or Post Primary (Leica, Zürich, Switzerland), then washed again in TBS, and incubated for $45 \mathrm{~min}$ in Flex + HRP (Dako) or Polymer (Leica). Another wash was performed and the slides were developed with $\mathrm{DAB}$ (Sigma) and counterstained with $\mathrm{HE}$, rinsed in water, and mounted with Aquatex. 
Table 1 GLP1R in human thyroid tissues

\begin{tabular}{|c|c|c|c|c|}
\hline & \multirow[b]{2}{*}{ Number of cases } & \multicolumn{2}{|c|}{ GLP1R IHC (positive cases vs total n) } & \multirow[b]{2}{*}{ Comments } \\
\hline & & $\begin{array}{l}\text { In glandular } \\
\text { tissue }\end{array}$ & $\begin{array}{l}\text { In } C \text { cells (identified } \\
\text { by calcitonin IHC) }\end{array}$ & \\
\hline \multirow[t]{4}{*}{ Normal thyroid } & $N=8$ (from normal thyroid samples) & $0 / 8$ & $0 / 8$ & \multirow[t]{4}{*}{$\begin{array}{l}\text { (Five cases tested by ARG and } \\
\text { confirmed as GLP1R negative) }\end{array}$} \\
\hline & $\begin{array}{l}N=4 \text { (from hyperplastic thyroid } \\
\text { samples) }\end{array}$ & $0 / 4$ & $0 / 4$ & \\
\hline & $\begin{array}{l}N=7 \text { (from papillary thyroid } \\
\text { carcinoma samples) }\end{array}$ & $0 / 7$ & $0 / 1$ & \\
\hline & $\begin{array}{l}N=4 \text { (from medullary thyroid } \\
\text { carcinoma samples) }\end{array}$ & $0 / 4$ & $0 / 1$ & \\
\hline C-cell hyperplasia & $N=8$ & $0 / 8$ & $0 / 8$ & \multirow{4}{*}{$\begin{array}{l}\text { Five cases tested by ARG and } \\
\text { confirmed as GLP1R negative } \\
\text { One case tested by ARG and } \\
\text { confirmed as GLP1R positive }\end{array}$} \\
\hline $\begin{array}{l}\text { Papillary thyroid } \\
\text { carcinoma }\end{array}$ & $N=8$ & \multicolumn{2}{|c|}{ In tumor cells } & \\
\hline Sporadic MTC & $N=10$ & & \\
\hline MEN 2 MTC & $N=10$ & \multicolumn{2}{|r|}{$0 / 10$} & \\
\hline
\end{tabular}

Abbreviations: ARG, GLP1R autoradiography; IHC, immunohistochemistry; MTC, medullary thyroid carcinoma.

\section{Western Blotting}

Approximately 50-100 mg fresh-frozen tumors were cut into small pieces, partially thawed, and washed in ice-cold PBS containing $1 \mathrm{mM}$ phenylmethylsulfonyl fluoride, incubated for $30 \mathrm{~min}$ at $4{ }^{\circ} \mathrm{C}$ in icecold lysis buffer $(20 \mathrm{mM}$ HEPES, $150 \mathrm{mM} \mathrm{NaCl}$, $5 \mathrm{mM}$ EDTA, $3 \mathrm{mM}$ EGTA, and $4 \mathrm{mg} / \mathrm{ml}$ dodecyl $\beta$-dmaltoside ( $\mathrm{pH}$ 7.6)) containing protease inhibitors ( $1 \mathrm{mM}$ phenylmethylsulfonyl fluoride, $10 \mu \mathrm{g} / \mathrm{ml}$ soybean trypsin inhibitor, $10 \mu \mathrm{g} / \mathrm{ml}$ leupeptin, $10 \mu \mathrm{g} / \mathrm{ml}$ aprotinin, and $50 \mu \mathrm{g} / \mathrm{ml}$ bacitracin), and homogenized in a tissue lyser Miller Mix for $2 \mathrm{~min}$ at $20 \mathrm{U} / \mathrm{s}$. The lysate was subsequently clarified by centrifugation at $16000 \mathrm{~g}$ and $4{ }^{\circ} \mathrm{C}$ for $30 \mathrm{~min}$ and subjected to partial purification by wheat germ agglutinin-agarose treatment. The adsorbed glycoproteins were eluted at $37^{\circ} \mathrm{C}$ for $30 \mathrm{~min}$ with sample buffer (400 mM Tris-HCl, 10\% SDS, 0.5 M 2-mercaptoethanol, $50 \%$ glycerol, and $0.025 \%$ Bromophenolblau) and resolved on a 10\% SDS-polyacrylamide gel. Resolved proteins were transferred to polyvinylidene difluoride membrane. The membrane was blocked for $2 \mathrm{~h}$ with $5 \%$ nonfat dry milk in TBSTween (TBS-T: $50 \mathrm{mM}$ Tris- $\mathrm{HCl}, 150 \mathrm{~mm} \mathrm{NaCl}$, and $0.1 \%$ Tween $20(\mathrm{pH} 7.4))$, and then incubated overnight at $4{ }^{\circ} \mathrm{C}$ with $1.78 \mu \mathrm{g} / \mathrm{ml}$ GLP1R-specific antibody (MAb 3F52) ${ }^{24}$ in TBS-T. Immunoreactive proteins were detected with a sheep antimouse IgG conjugated with horseradish peroxidase $(1: 2000)$ in TBS-T, and the ECL chemiluminescent antibody detection system (GE Healthcare, Little Chalfont, UK).

\section{In Vitro GLP1R Autoradiography}

The in vitro GLP1R autoradiography was carried out as described previously. ${ }^{2,21}$ Thick frozen tissue sections $(20 \mu \mathrm{m})$ were incubated for $2 \mathrm{~h}$ at room temperature in the incubation solution containing $170 \mathrm{mM}$ Tris-HCl buffer ( $\mathrm{pH}$ 8.2), 1\% bovine serum albumin (BSA), $40 \mu \mathrm{g} / \mathrm{ml}$ bacitracin, $10 \mathrm{mM}$ $\mathrm{MgCl}_{2}$, and 15000 c.p.m./100 $\mu{ }^{125}$ I-GLP1(7-36)amide (2000 Ci $/ \mathrm{mmol}$; Anawa, Wangen, Switzerland). Nonspecific binding was determined by incubating tissue sections in the incubation solution containing additionally $100 \mathrm{nM}$ unlabeled GLP1(7-36) amide (Bachem, Bubendorf, Switzerland) that, at this concentration, completely and specifically displaces ${ }^{125}$ I- GLP1(7-36)amide at the receptors. After incubation, the slides were washed five times in icecold Tris-HCl buffer ( $170 \mathrm{mM}$; pH 8.2 ) containing $0.25 \%$ BSA and twice in ice-cold Tris-HCl buffer without BSA. The slides were dried for $15 \mathrm{~min}$ under a stream of cold air and exposed to Kodak Biomax MR films for 7 days at $4{ }^{\circ} \mathrm{C}$. The signals were analyzed in correlation with morphology using corresponding HE-stained tissue slides. The receptor density was quantitatively assessed using tissue standards for iodinated compounds (Amersham, Aylesbury, UK) and a computer-assisted image processing system (Analysis Imaging System, Interfocus, Mering, Germany).

\section{Results}

\section{Controls}

The detailed sequential description of the figures is given in the legends. Figure 1 depicts two GLP1R-expressing human control tissues as complementary validation of the GLP1R immunoreactivity, as revealed by the MAb 3F52 (Figure 1a and e), together with GLP1R in situ ligand binding as shown by autoradiography (Figure $1 \mathrm{~b}-\mathrm{d}$ and $\mathrm{f}-\mathrm{h}$ ). Two established human GLP1 targets, the duodenal 
Table 2 GLP1R in human pancreatic tissues

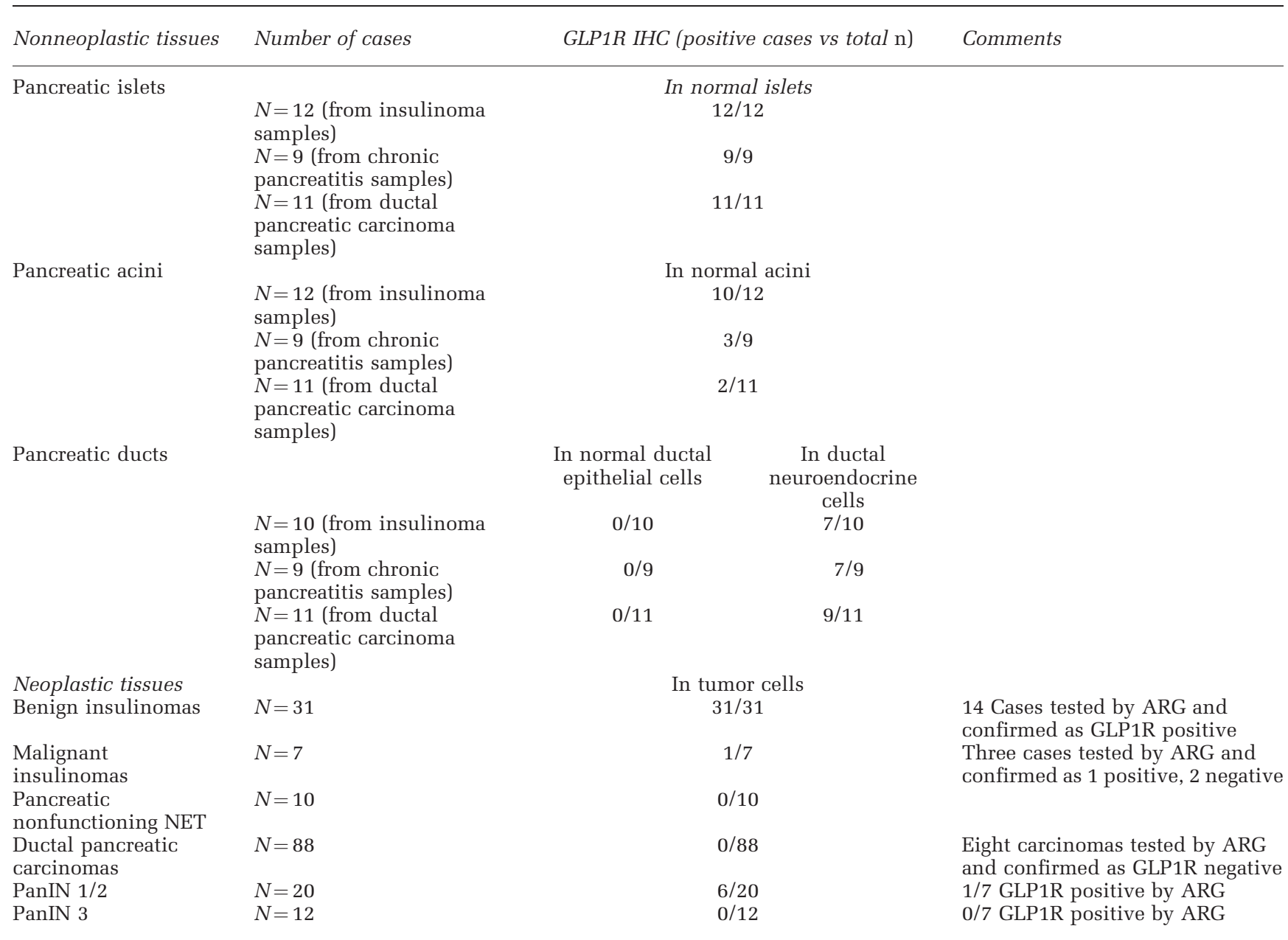

Abbreviations: ARG, GLP1R autoradiography; IHC, immunohistochemistry.

Brunner glands (Figure 1a-d) and the pancreatic islets (Figure 1e-h), known to be GLP1R positive with receptor autoradiography, are also found GLP1R positive by immunohistochemistry (Figure 1a and e). Most importantly, the immunostaining of these tissues is strongly membrane bound (insets, Figure 1a and e). Such a membranous staining is expected as G protein-coupled receptors (GPCRs; GLP1R is a GPCR) are defined as cell surface receptors. In the present study, we considered membranous staining to be an obligatory feature of GLP1Rspecific immunoreactivity, whereas diffuse intracellular staining was not considered to be specific for GLP1R.

\section{Thyroid}

As shown in Table 1, none of the human thyroid samples with normal or hyperplastic C cells were found positive for GLP1R, neither in the glandular tissue nor in the $\mathrm{C}$ cells that were identified by calcitonin immunohistochemistry. These results were independent of the type of thyroid pathology present in the surroundings of the normal thyroid tissue (Table 1).

Figure 2a-d (normal thyroid) and Figure $2 \mathrm{~h}-\mathrm{k}$ (thyroid and C-cell hyperplasia) illustrate that none of the $\mathrm{C}$ cells identified by calcitonin immunohistochemistry were GLP1R positive. Figure2e-g documents that the normal thyroid is also GLP1R negative by autoradiography.

The nine papillary thyroid carcinomas did not express GLP1R (Figure 2l-p), neither by immunohistochemistry nor by autoradiography in five cases where both formalin-fixed and fresh-frozen tissues were available; the tumor cells in $2 / 10$ sporadic medullary thyroid carcinomas were GLP1R positive by immunohistochemistry (Table 1). The receptor distribution was not homogenous in the tumor sample, as seen in Figure $2 \mathrm{q}$ and $\mathrm{r}$. The inset in Figure 2r shows that the GLP1R are membrane bound. Figure $2 \mathrm{~s}-\mathrm{u}$ shows that this particular tumor was also positive in GLP1R autoradiography. Conversely, all 10 familial MEN 2 medullary thyroid 

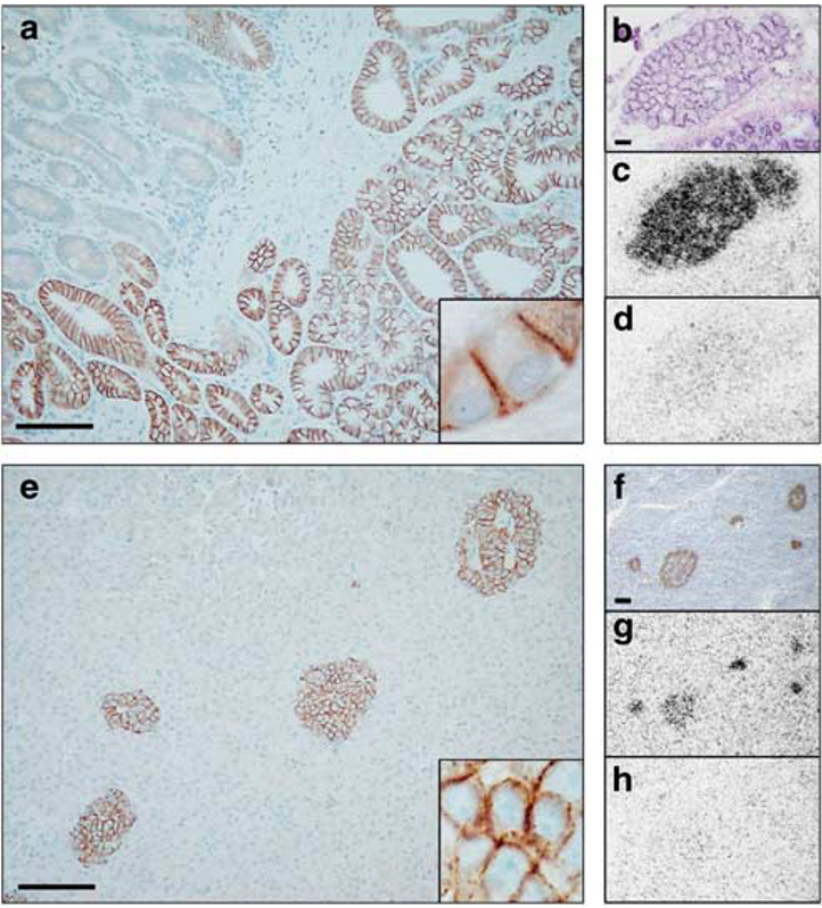

Figure 1 Comparison of GLP1R immunohistochemistry with ${ }^{125} \mathrm{I}$ GLP1(7-36)-amide receptor autoradiography in two representative examples of GLP1R-expressing human tissues: the Brunner's glands (a-d) and the pancreatic islets (e-h). Brunner's gland: (a) Strong membranous GLP1R immunostaining of the glands. Bar $=0.1 \mathrm{~mm}$. Insert shows strong membranous staining. (b-d) Receptor autoradiography on tissue sections of the same case showing the hematoxylin and eosin-stained tissue ( $\mathrm{bar}=0.1 \mathrm{~mm}$ ) in (b), very strong total ${ }^{125}$ I- GLP1(7-36)-amide binding to the glandular tissue in (c), and complete displacement of ${ }^{125} \mathrm{I}-$ GLP1(7-36)-amide by cold GLP1 in (d), providing evidence of specificity of GLP1R binding. There is an excellent correlation between strong GLP1R immunostaining and high ${ }^{125}$ I- GLP1(736)-amide binding levels. Pancreatic islets: (e) GLP1R immunostaining of the islets (bar $=0.1 \mathrm{~mm}$ ) is shown. Insert shows the strong membranous staining. This immunostaining corresponds well with the strong specific ${ }^{125}$ I- GLP1(7-36)-amide binding to the pancreatic islets of the same case in the autoradiography experiment (f-h). (f) Synaptophysin immunostaining. Bar $=0.1$ $\mathrm{mm}$. (g) Total ${ }^{125}$ I- GLP1(7-36)-amide binding. (h) Nonspecific binding.

carcinomas were GLP1R negative by immunohistochemistry (Table 1).

\section{Pancreas}

As shown in Table 2, all pancreatic islets were found to be GLP1R positive, irrespective of whether they originate from samples containing insulinoma, chronic pancreatitis, or ductal pancreatic carcinoma. As seen in Figure 3a and b, the GLP1Rexpressing cells corresponded to insulin-producing cells. The GLP1Rs were located at the cell membrane (Figure 3a). In areas of the pancreas containing PP-expressing cells (Figure 3h), the GLP1Rs (Figure 3j) were not expressed in the PP cells but only in the few surrounding insulin cells (Figure 3i). The receptors are located at the cell membrane
(Figure 3k). Furthermore, although glucagon cells were not found receptor positive (Figure $3 \mathrm{l}$ and $\mathrm{m}$ ), the somatostatin cells in the islets expressed GLP1R (Figure 3n and o). Moreover, single insulinproducing endocrine cells distributed within the pancreas (Figure 3u) were also GLP1R positive (Figure 3t).

A low density of GLP1R was found in the pancreatic acini (Table 2). Whereas the great majority of the samples had GLP1R-expressing acini (Figure 3c), their distribution was often heterogeneous. Rare samples even remained negative (Table 2; Figure 3a, at the periphery of the immunoreactive islet). As also seen in Figure 3c and d, the GLP1R in acini are membrane bound. The weak GLP1R immunohistochemical staining is compatible with the low GLP1R density seen in autoradiography (Figure $3 \mathrm{e}-\mathrm{g}$ ), where the acinar structure cannot be seen because of the low resolution of the technique. Interestingly, although the great majority of samples originating from insulinoma cases had GLP1R-expressing acini, the percentage of cases with positively immunostained acini was lower in samples originating from chronic pancreatitis or ductal pancreatic carcinoma (Table 2).

The normal pancreatic duct epithelial cells were always GLP1R negative, irrespective of whether the samples originated from insulinomas, chronic pancreatitis, or ductal pancreatic carcinoma samples. Conversely, single neuroendocrine cells in the ducts, identified by synaptophysin, chromogranin, or insulin staining, were frequently expressing GLP1R (Table 2). Figure 3p-s shows GLP1R-negative ducts. In an otherwise receptor-negative duct, there is a single GLP1R-expressing (Figure 3r) neuroendocrine insulin-secreting cell (Figure 3s). Finally, pancreatic stellate cells (Figure 3v) were always found to be GLP1R negative (Figure 3w).

\section{Pancreatic Neoplasia}

As expected from previous in situ ligand-binding studies, ${ }^{3,26}$ all 32 benign insulinomas were positive for GLP1R by immunostaining (Table 2). Figure 4a and $b$ shows a representative case of benign insulinoma positively immunostained for GLP1R (Figure 4a). Virtually all cells are stained and the receptors are membrane bound. This illustrated case is also strongly GLP1R positive by autoradiography (Figure 4c-e). Conversely, only one of six malignant insulinomas was positive with GLP1R immunostaining. A typical malignant insulinoma is shown in Figure $4 \mathrm{f}-\mathrm{j}$ that is negative for both GLP1R immunohistochemistry (Figure 4f) and autoradiography (Figure $4 \mathrm{~h}-\mathrm{j}$ ).

Table 3 shows a summary of the semiquantitative GLP1R measurement by immunohistochemistry in all tested insulinomas. The results are expressed in four categories of staining intensity, as percentage of labeled cells, as reported previously. ${ }^{27}$ These data 

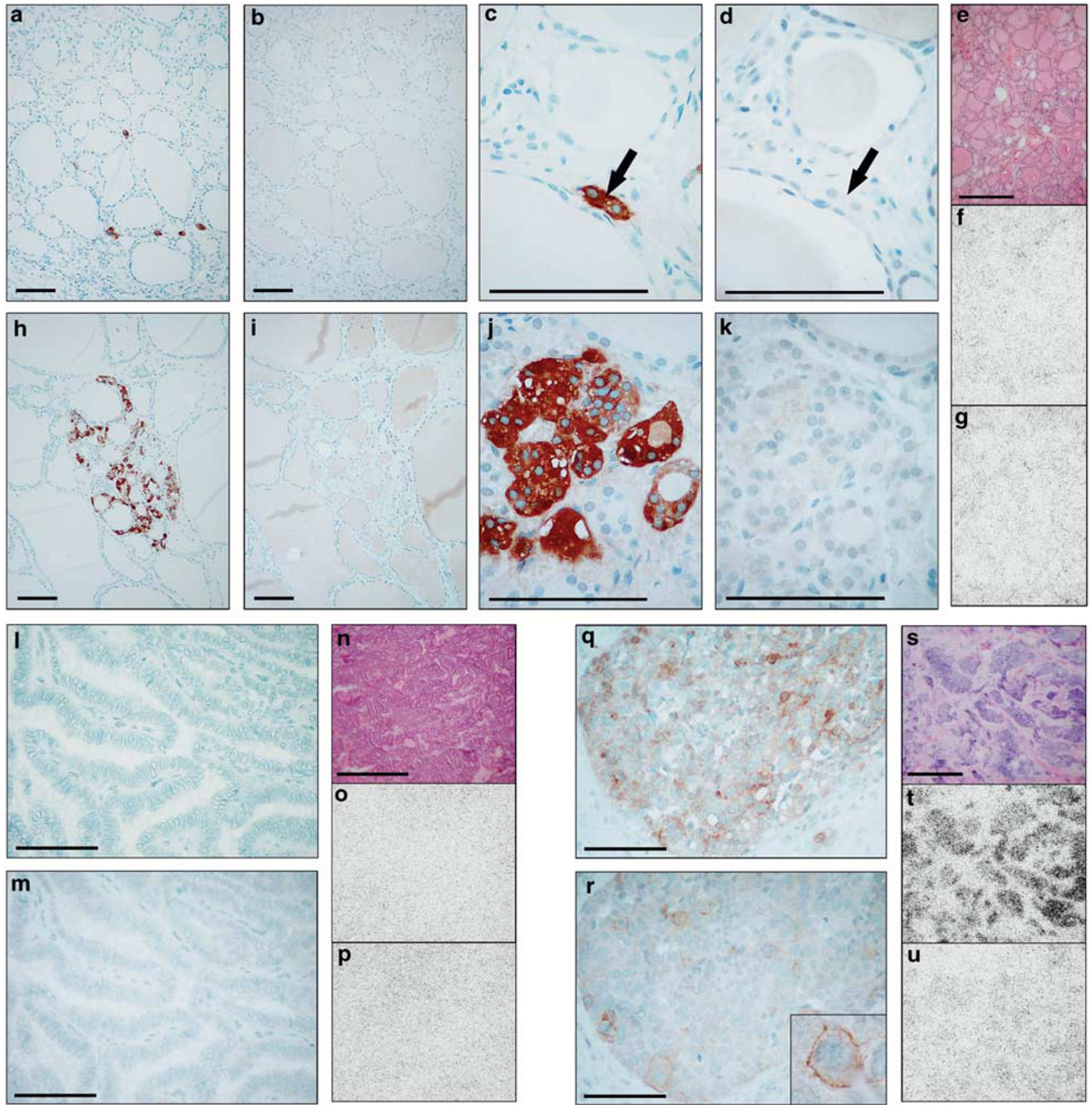

Figure 2 GLP1R immunohistochemistry in human nonneoplastic and neoplastic thyroid tissues as compared with GLP1R autoradiography. (a-d) Absence of GLP1R in the normal human thyroid. (a, c) Calcitonin immunohistochemistry shows normal C cells (arrow). Bars $=0.1 \mathrm{~mm}$. (b, d) GLP1R immunostaining is negative in the adjacent serial tissue sections. A high magnification confirms that the two C cells (arrow) (c) do not express GLP1R (d). (e-g) GLP1R autoradiography showing absence of GLP1R in the normal human thyroid. (e) Hematoxylin and eosin staining. Bar $=1 \mathrm{~mm}$. (f) Total binding. (g) Nonspecific binding. (h-k) Absence of GLP1R in C-cell hyperplasia of the thyroid. (h) Calcitonin immunohistochemistry shows a C-cell hyperplastic area (h) that is not immunostained for GLP1R (i). Bars $=0.1 \mathrm{~mm}$. (j, k) At higher magnification, the calcitonin-stained hyperplastic C cells (j) do not immunostain for GLP1R (k). (l-p) Absence of GLP1R in papillary thyroid cancer (PTC). The calcitonin-negative (l) PTC is not immunoreactive for the GLP1R (m). Bars $=0.1 \mathrm{~mm}$. GLP1R autoradiography (n--p) confirms absence of GLP1R in this same tumor case. (n) Hematoxylin and eosin staining. Bar $=1 \mathrm{~mm}$. (o) Total binding. (p) Nonspecific binding. (q-u) GLP1Rs are expressed in a medullary thyroid carcinoma. The calcitonin immunopositive tumor $(\mathbf{q})$ has a focal distribution of GLP1R detected by GLP1R immunohistochemistry $(\mathbf{r})(\mathrm{bar}=0.1 \mathrm{~mm})$; membranous staining is shown in the inset. GLP1R autoradiography (s-u) confirms the presence of GLP1R in this tumor. (s) Hematoxylin and eosin staining. Bar $=1 \mathrm{~mm}$. (t) Total binding. (u) Nonspecific binding.

are compared with the quantitative detection of GLP1R by autoradiography, tested in those cases available with both formalin-fixed and fresh-frozen material. The great majority of the benign insulinomas have a high density of GLP1R, as measured with both methods, whereas malignant insulinomas are 

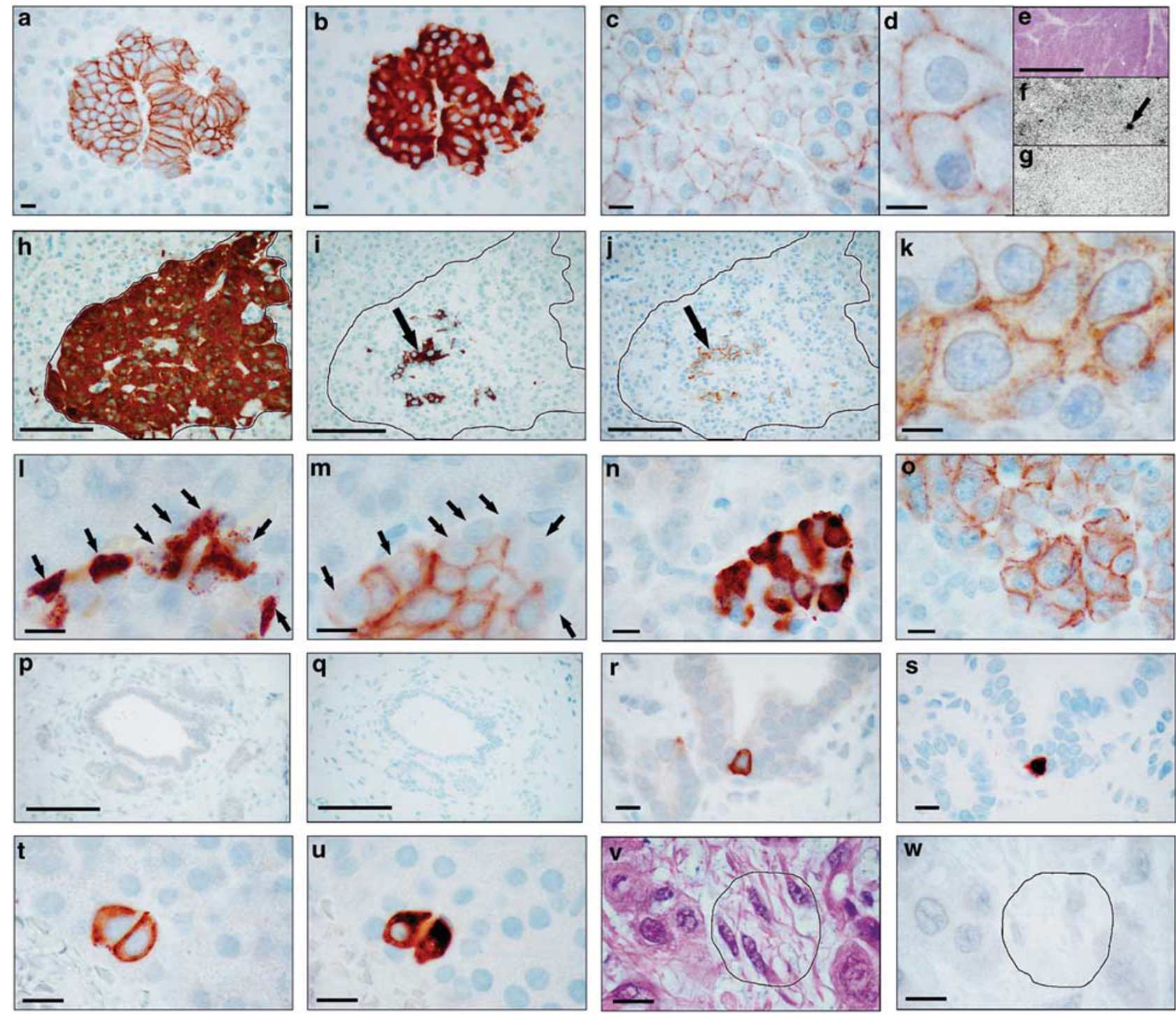

Figure 3 GLP1R immunohistochemistry in the normal human pancreas. GLP1R immunohistochemistry in a pancreatic islet (a) localized in the insulin-producing cells (b, insulin immunohistochemistry). This area of the sample has no measurable levels of GLP1R in acini. Bars $=0.01 \mathrm{~mm}$. (c, d) GLP1R immunohistochemistry in the majority of pancreatic acinar cells. Strong membranous staining, also seen in the magnified illustration (d). Bars $=0.01 \mathrm{~mm}$. (e-g) GLP1R autoradiography of the same pancreas as in (c, d). (e) Hematoxylin and eosin staining. Bar $=1 \mathrm{~mm}$. (f) Total binding of ${ }^{125} \mathrm{I}-$ GLP1(7-36)-amide showing a diffuse weak binding in the acinar area and a strong binding in one islet (arrow). (g) Nonspecific binding. (h-k) GLP1R immunohistochemistry in a pancreatic polypeptide (PP)-rich area (delimited by black line in $\mathbf{h}, \mathbf{i}, \mathbf{j}$ ) of the pancreas. (h) Immunoreactive PP. (i) Insulin immunohistochemistry on adjacent serial section. (j) GLP1R immunohistochemistry on adjacent section. Bars $=0.1 \mathrm{~mm}$. GLP1Rs are localized in the insulin cells (arrows), and not in the PP cells. (k) The membranous GLP1R staining, magnified from (j). Bar $=0.01 \mathrm{~mm}$. (l, m) Lack of GLP1R immunostaining (m; arrows) in glucagonexpressing islet cells (l; arrows). Bars $=0.1 \mathrm{~mm}$. (n, o) GLP1R immunohistochemistry in somatostatin-expressing islet cells (n). All somatostatin cells have GLP1R (o). Bars $=0.1 \mathrm{~mm}$. (p, q) Lack of GLP1R immunostaining in normal pancreatic ducts (p). Adjacent serial section with hematoxylin staining (q). Bars $=0.1 \mathrm{~mm}$. (r, s) Endocrine cell positively immunostained for GLP1R in an otherwise receptornegative duct $(\mathbf{r})$. This cell is insulin producing $(\mathbf{s})$. Bars $=0.1 \mathrm{~mm}$. (t, u) Single cells in the pancreatic acinar area positively immunostained for GLP1R (t). These two cells are insulin producing $(\mathbf{u})$. Bars $=0.01 \mathrm{~mm}$. $(\mathbf{v}, \mathbf{w})$ Stellate cells of the human pancreas (area within the black line) do not express GLP1R. (v) Hematoxylin and eosin staining. (w) GLP1R immunohistochemistry. Bars $=0.01$ mm.

usually negative (Table 3). To confirm that the reported immunohistochemistry of benign insulinomas with antibody MAb 3F52 identifies true GLP1R, a western blotting was performed in one of the immunohistochemistry-positive tumors for which fresh-frozen tissue was available. Figure 5a shows a single band at $\sim 53 \mathrm{kDa}$ corresponding to GLP1R in this benign insulinoma. The western blot in
Figure 5d shows a GLP1R-negative malignant insulinoma as negative control.

Pancreatic nonfunctioning neuroendocrine tumors were found to be all GLP1R negative (Table 2). Furthermore, all 88 ductal pancreatic carcinomas were found to be GLP1R negative by immunohistochemistry in the carcinoma cells. An example of an immunohistochemistry-negative ductal pancreatic 
carcinoma is shown in Figure 4k and l, with confirmation of the lack of GLP1R by autoradiography (Figure $4 \mathrm{~m}-0$ ). A total of eight ductal carcinomas were tested for GLP1R autoradiography and were confirmed as GLP1R negative (Table 2). Interestingly, however, 6/32 cases (18\%) of PanIN were GLP1R positive by immunohistochemistry (Table 1). The six positive PanIN were all diagnosed as PanIN 1 or 2; they belonged to patients with GLP1R-negative ductal pancreatic carcinomas. Two of the PanIN 1/2 receptor-positive samples had adjacent PanIN 3 areas that were GLP1R negative. The other 12 tested cases of PanIN 3 were all GLP1R negative (Table 2). Figure $4 \mathrm{p}$ and $\mathrm{q}$ shows a GLP1R-positive PanIN 1. From the 14 cases of PanIN tested by GLP1R autoradiography on cryostat sections, 1 of 7 cases of PanIN 1/2 stage was receptor positive, whereas 0 of 7 cases of PanIN 3 stage was positive (Table 2).

\section{Discussion}

The present report is based on an extensive immunohistochemical study of the GLP1R status in human thyroid and pancreatic tissues with a specific and well-validated monoclonal GLP1R antibody, ${ }^{24}$ and also compares and further validates the obtained data with in situ ligand binding. Because of previous studies in this field using poorly characterized antibodies, ${ }^{22,25}$ we took particular care to use a thoroughly validated monoclonal antibody that specifically labels GLP1R-expressing cells while being negative for GLP1R-lacking cells, ${ }^{23,24}$ and that has a superior immunohistochemical specificity compared with several other (commercial) GLP1R antibodies. ${ }^{23}$ As further proof of specificity and validation, we reported in the present study the results of specific GLP1R immunostaining in established human GLP1R targets such as endocrine pancreas or Brunner's gland and compared these results with the data of an alternative method of GLP1R measurement, namely GLP1R autoradiography in the same tissues. Furthermore, we confirmed that immunohistochemistry of human insulinoma identifies true GLP1R by demonstrating the presence of such receptors in western blots of the same tissue. Finally, we considered only membrane-bound GLP1R immunohistochemistry as truly specific, a basic request for the immunohisto- chemical characterization of all GPCRs, ${ }^{28}$ to which family the GLP1Rs also belong.

The present results show definitely that the normal human thyroid, in particular the $\mathrm{C}$ cells, do not express GLP1R. C-cell hyperplastic human thyroids do not express GLP1R either. This is now well documented with two different methods: immunohistochemistry (in the present study) or autoradiography. ${ }^{2,21}$ It confirms previous findings suggesting a strong species difference in the GLP1R expression in the thyroid, with high levels in normal and hyperplastic rat thyroids but with complete absence of such receptors in the human organ. ${ }^{2,21}$ The lack of GLP1R in the human thyroid in the present study is in contrast with the immunohistochemistry study by Gier et $a l^{22}$ that showed the presence of immunostained GLP1R in the human thyroid. The explanation for the discrepancy is likely to be that the antibody used by Gier et $a l^{22}$ was not sufficiently specific, therefore eliciting questionable results. ${ }^{11,23}$

We could not find GLP1R in any of the human papillary thyroid carcinomas, neither by immunohistochemistry nor by autoradiography, again as opposed to Gier et al, ${ }^{22}$ who found immunoreactivity attributed to GLP1R in $18 \%$ of the cases, but based on an insufficiently validated immunohistochemical protocol. ${ }^{11,23}$

Conversely, a minority of sporadic medullary thyroid carcinomas, namely $2 / 10(20 \%)$, did express a measurable amount of GLP1R by immunohistochemistry in our study. Interestingly, the 10 familial medullary thyroid carcinomas of the MEN 2 type, however, were all found to be negative for these receptors. The low percentage of GLP1R-positive medullary thyroid carcinomas corresponds well to previous data obtained with autoradiography, with $28 \%$ positivity. ${ }^{2,21}$ These low numbers, however, differ markedly from the high incidence (11/12; $92 \%$ ) found by Gier et al. ${ }^{22}$

The present study indicates that not only insulinproducing cells in the islets express GLP1R, but that the latter can also be expressed by virtually all insulin-producing cells in the pancreas. This is true for the insulin cells in the PP-rich areas (the PP cells, however, are GLP1R negative); it is true for the single insulin cells distributed throughout the pancreas and it is also true for the insulin-producing endocrine cells localized in the pancreatic ducts.

\footnotetext{
Figure 4 GLP1R immunohistochemistry in neoplastic human pancreas tissues compared with GLP1R autoradiography in the same cases. (a-e) GLP1R-expressing benign insulinoma. (a) GLP1R immunohistochemistry showing strong membranous staining in all tumor cells. (b) Positive insulin immunohistochemistry in an adjacent serial section. Bars $=0.01 \mathrm{~mm}$. (c-e) GLP1R autoradiography showing strong GLP1R expression in the whole tumor of the same case. (c) Hematoxylin and eosin staining. Bar $=1 \mathrm{~mm}$. (d) Total binding. (e) Nonspecific binding. (f-j) GLP1R-negative malignant insulinoma. (f) GLP1R immunohistochemistry shows absence of GLP1R. (g) Insulin immunohistochemistry on adjacent serial section. Bars $=0.01 \mathrm{~mm}$. (h-j) GLP1R autoradiography of the same case showing absence of GLP1R. (h) Hematoxylin and eosin staining. Bar =1 mm. (i) Total binding. (j) Nonspecific binding. (k-o) GLP1R-negative pancreatic ductal carcinoma. (k) GLP1R immunohistochemistry shows absence of GLP1R. (l) Hematoxylin and eosin-stained adjacent section. Bars $=0.1 \mathrm{~mm}$. (m-o) GLP1R autoradiography showing absence of GLP1R. (m) Hematoxylin and eosin staining. Bar=1 mm. (n) Total binding. (o) Nonspecific binding. (p, q) PanIN 1 case positively immunostained for GLP1R (p). Membranous staining. (q) Hematoxylin and eosin stained adjacent serial section. Bars $=0.01 \mathrm{~mm}$.
} 
It is therefore probable that GLP1 will have a similar physiological role on insulin in the islet cells, as currently believed, as in all the other nonislet insulin-producing pancreatic cells, through specific GLP1R. This statement can also be extended to the role of the GLP1-like drugs used for diabetes
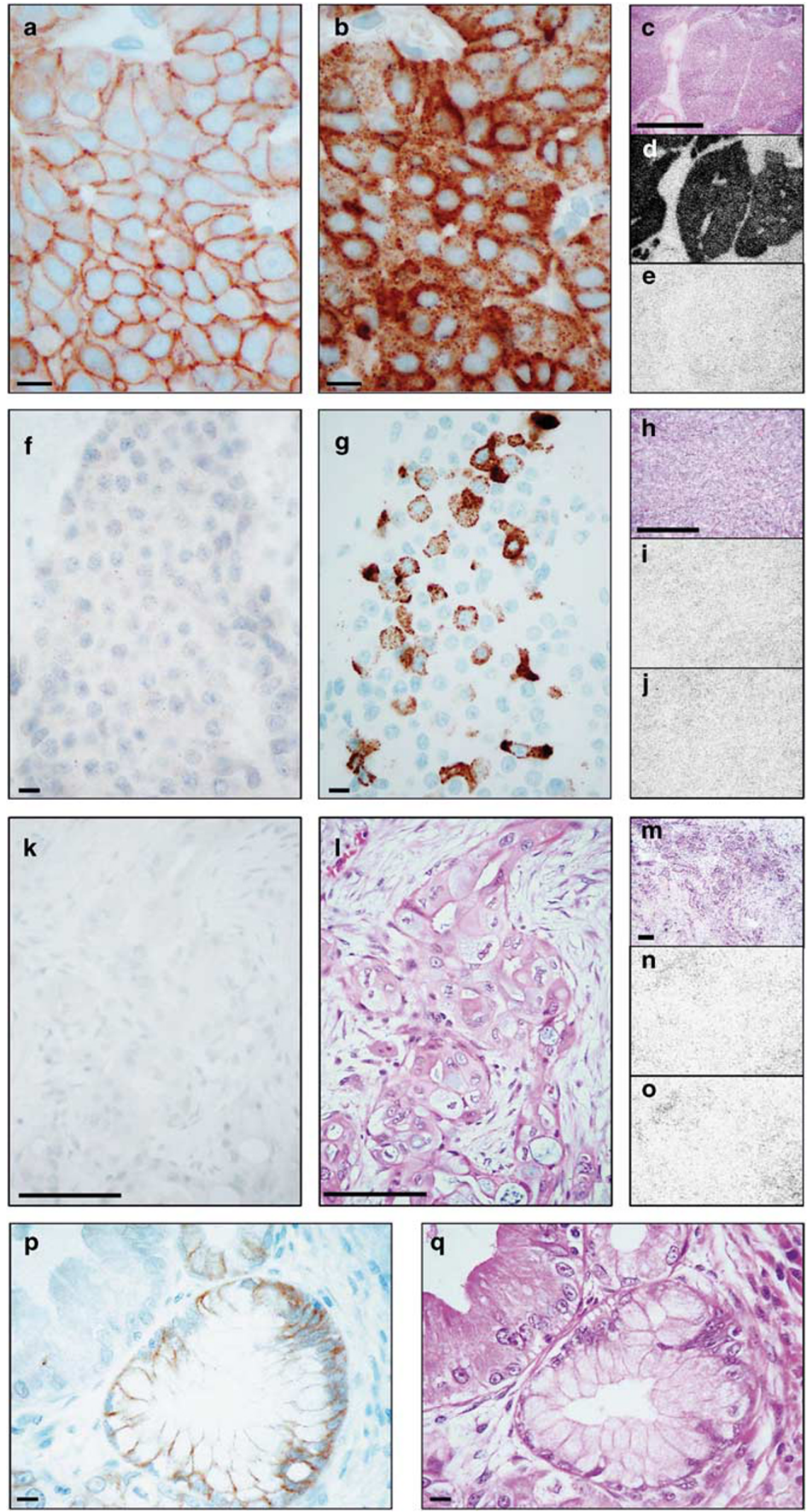
Table 3 GLP1R in insulinomas: semiquantitative GLP1R immunohistochemistry and quantitative ARG in corresponding cases

GLP1R IHC

\begin{tabular}{|c|c|c|c|c|}
\hline Staining intensity ${ }^{\mathrm{a}}$ & $\begin{array}{l}\text { No. of } \\
\text { cases }\end{array}$ & $\begin{array}{l}\text { Membranous staining } \\
\text { No. of cases }\end{array}$ & $\begin{array}{l}\% \text { Of positive } \\
\text { cells (mean) }\end{array}$ & $\begin{array}{c}R \text { density (d.p.m./mg tissues) } \\
\text { (mean } \pm \text { s.e.m.) }\end{array}$ \\
\hline \multicolumn{5}{|l|}{ Benign insulinomas } \\
\hline High receptor density/staining intensity $(3+)$ & 15 & 15 & $97 \%$ & $7132 \pm 817(n=8)$ \\
\hline Moderate receptor density/staining intensity $(2+)$ & 11 & 11 & $83 \%$ & $4590 \pm 1443(n=5)$ \\
\hline Low receptor density/staining intensity $(1+)$ & 5 & 5 & $37 \%$ & $3104(n=1)$ \\
\hline No receptor/no staining & 0 & - & - & 0 \\
\hline \multicolumn{5}{|l|}{ Malignant insulinomas } \\
\hline High receptor density/staining intensity $(3+)$ & 1 & 1 & $100 \%$ & 6480 \\
\hline No receptor/no staining & 2 & - & - & 0 \\
\hline
\end{tabular}

GLP1R ARG

$R$ density (d.p.m./mg tissues) (mean \pm s.e.m.)

Abbreviation: ARG, autoradiography.

${ }^{\text {a }}$ Staining intensity according to Körner et al. ${ }^{27}$.

treatment, targeted to these different types of insulin-producing cells. In addition to insulinproducing islet cells, the somatostatin-producing islet cells also express GLP1R, whereas glucagonproducing cells appear to lack such receptors.

As reported previously, we confirm autoradiography and immunohistochemistry data ${ }^{2,24}$ showing that human pancreatic acini do express GLP1R, although in much lower density than the insulinproducing cells. As opposed to the small population of GLP1-expressing endocrine cells, the fact that a large part of the pancreatic acinar population expresses GLP1R, even in low density, indicates that there is a considerable amount of nonendocrine GLP1R in the pancreas, for which a physiological role is not yet known. The presence of GLP1R in acini may jeopardize the effort to successfully perform imaging on $\beta$-cell mass using radiolabeled GLP1 analogs in the human pancreas. ${ }^{10}$

A marginal observation of this study is that acinar GLP1Rs seem to be reduced in chronic pancreatitis and in ductal pancreatic carcinoma samples as opposed to insulinoma samples. A similar observation was made previously with quantitative GLP1R autoradiography. ${ }^{2}$ Interestingly, in an animal model of pancreatitis, it was recently found that, contrary to the present data, GLP1Rs were increased in acini and ducts. ${ }^{29}$ This discrepancy may suggest once more that animal models may differ from settings in humans, making extrapolations from animals to humans difficult. ${ }^{11,21}$ Interestingly, Gier et $a l^{25}$ did not detect GLP1R in human acini with their immunohistochemistry protocol.

The pancreatic duct epithelial cells in any of the tested samples did not express GLP1R, with the exception of occasional endocrine insulin-producing cells. The absence of GLP1R is in agreement with the results of another immunohistochemistry study, ${ }^{24}$ an autoradiography study, ${ }^{2}$ and of an mRNA study, ${ }^{11}$ but is in conflict with the study by Gier et $a l^{25}$ showing GLP1R in ducts by immunohistochemistry. As the validation of the antibody used in the study by Gier et $a l^{25}$ was incomplete, we may assume that the convergent results of the four other studies showing absence of GLP1R in human duct epithelial cells correspond more closely to the reality. This implies that the normal ducts would not be a potential target for GLP1 drugs during diabetes therapy.

The tissues that by far express the highest levels of GLP1R are specific neuroendocrine tumors of the pancreas, the benign insulinomas. This was discovered a decade ago by receptor autoradiography. ${ }^{3}$ It led subsequently to the successful development of in vivo targeting of insulinomas by using radiolabeled exendin analogs. ${ }^{7-9}$ The present study shows for the first time that it is possible to perform immunohistochemistry to easily diagnose the presence of GLP1R in these tumors in formalinfixed tissues. For specificity control and antibody validation, we directly compared GLP1R immunohistochemistry with quantitative GLP1R autoradiography in a large number of these insulinomas and further provided a western blot of one of the immunohistochemistry-positive insulinoma, revealing a single band corresponding to GLP1R. GLP1R immunohistochemistry with antibody MAb 3F52 may therefore become a useful tool to measure GLP1R in tissue samples of neuroendocrine tumors submitted for histopathologic examination, as it is already the case for somatostatin receptor immunohistochemistry in neuroendocrine tumors. ${ }^{27}$ As also reported in the present study, there are considerable differences in GLP1R expression within pancreatic endocrine tumor types, with large amounts being present in benign insulinomas, a low incidence in malignant insulinomas, and a lack of GLP1R in nonfunctioning pancreatic neuroendocrine tumors.

Confirming previous GLP1R autoradiography data, ${ }^{2}$ we did not find any ductal pancreatic carcinoma expressing GLP1R in the tumor cells. However, because Gier et $a l^{25}$ claimed that PanIN may express GLP1R in a large percentage of cases, we examined a large number of PanIN cases. 

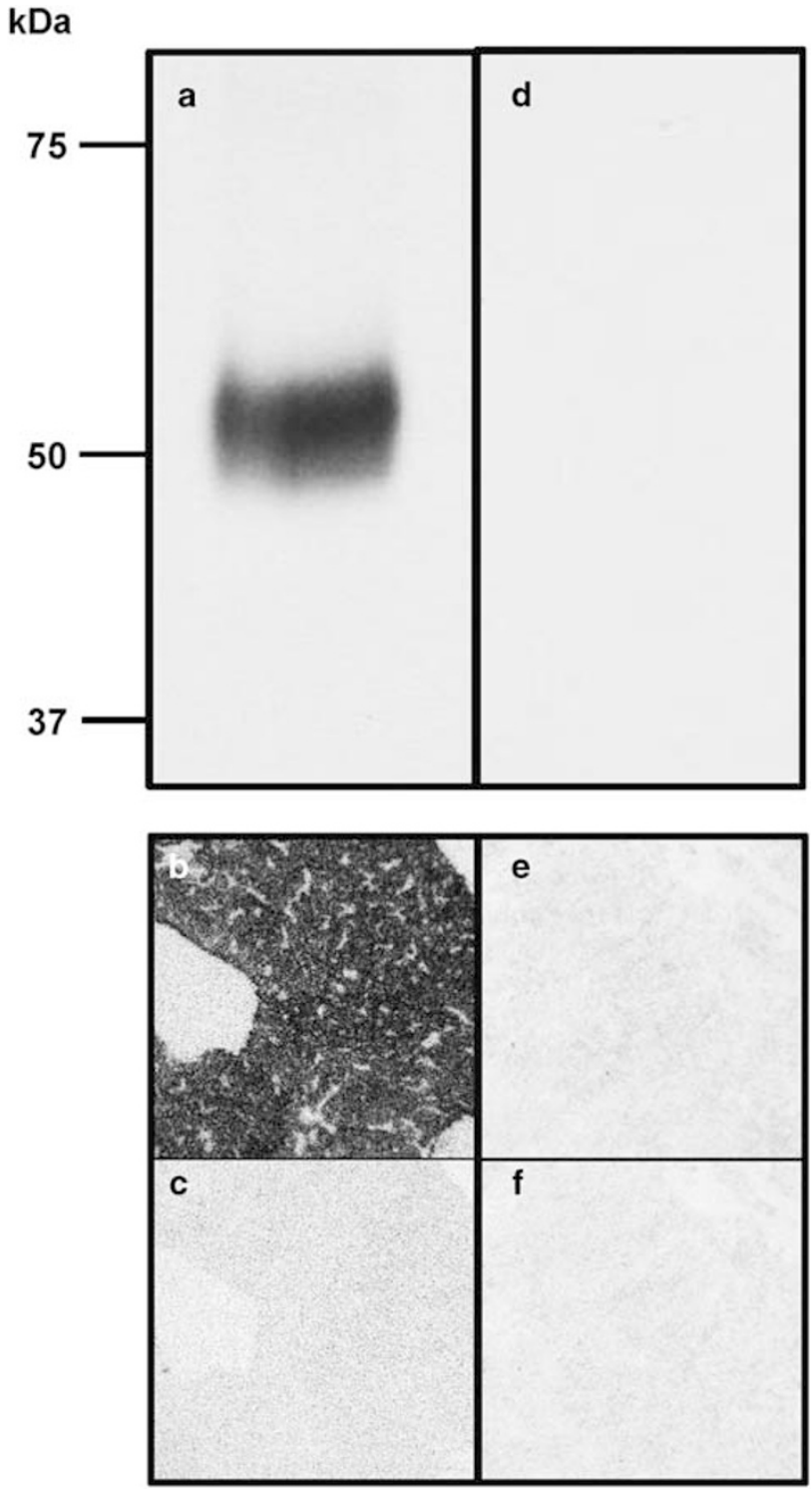

Figure 5 Western blot analysis providing evidence of the specificity of staining for GLP1R in a benign insulinoma (a), found to be strongly positive in autoradiography (b, total binding; c, nonspecific binding). There is a single broad band migrating at $\sim 53 \mathrm{~kb}$, the expected size of GLP1R. In the right column, as negative control, absence of a band (d) in a malignant insulinoma, also negative by autoradiography (e, f).

Whereas the present results show that $6 / 32$ cases were GLP1R positive, representing $18 \%$ of all our PanIN cases, it should be stressed that the 6 positive cases were all of the PanIN 1/2 type, and that the 12 cases with PanIN 3 were all negative. As neither normal ducts nor PanIN 3 lesions nor pancreatic carcinoma cells express GLP1R in a measurable way, the GLP1R in PanIN 1/2 may be understood as a rare and probably transient phenomenon that is not necessarily involved in neoplastic transformation.

What do the findings of the present study mean with regard to the strategy of treating diabetes with GLP1 analogs? The absence of GLP1R in normal and hyperplastic $\mathrm{C}$ cells of the thyroid clearly indicates that these tissues are unlikely targets for GLP1 analogs in humans. However, diabetic patients with concomitant sporadic medullary thyroid carcinomas that express GLP1R in $20-30 \%$ should probably be excluded from any incretin treatment for their diabetes. Such patients may be identified by in vivo imaging using radiolabeled exendin, a procedure also performed for the detection of insulinomas. ${ }^{7,8}$ Normal human pancreas as well as the chronically inflamed pancreas express GLP1R, as expected, primarily in the therapeutic targets of GLP1 analogs, namely the insulin-producing cells. The normal ducts, however, lack GLP1R and are therefore not a likely target for GLP1 analogs. The only other exocrine compartment with a consistent GLP1R expression is constituted by the acini, in which no clear function for GLP1 has been found up to now. Finally, the fact that normal ducts, ductal pancreatic carcinomas, or PanIN 3 do not express GLP1R indicate that GLP1Rs are unlikely to be related to neoplastic transformation in the pancreas.

\section{Disclosure/conflict of interest}

The authors declare no conflict of interest.

\section{References}

1 Holst JJ. The physiology of glucagon-like peptide 1. Physiol Rev 2007;87:1409-1439.

2 Körner M, Stockli M, Waser B, et al. GLP-1 receptor expression in human tumors and human normal tissues: potential for in vivo targeting. J Nucl Med 2007;48:736-743.

3 Reubi JC, Waser B. Concomitant expression of several peptide receptors in neuroendocrine tumors as molecular basis for in vivo multireceptor tumor targeting. Eur J Nucl Med 2003;30:781-793.

4 Holst JJ, Vilsboll T, Deacon CF. The incretin system and its role in type 2 diabetes mellitus. Mol Cell Endocrinol 2009;297:127-136.

5 Drucker DJ, Dritselis A, Kirkpatrick P. Liraglutide. Nat Rev Drug Discov 2010;9:267-268.

6 Drucker DJ, Nauck MA. The incretin system: glucagonlike peptide-1 receptor agonists and dipeptidyl peptidase-4 inhibitors in type 2 diabetes. Lancet 2006;368: 1696-1705.

7 Wild D, Mäcke H, Christ E, et al. Glucagon-like peptide 1-receptor scans to localize occult insulinomas. N Engl J Med 2008;359:766-768.

8 Christ E, Wild D, Ederer S, et al. Glucagon-like peptide-1 receptor imaging for the localisation of insulinomas: a prospective multicentre imaging study. Lancet Diabetes Endocrinol 2013;1:115-122.

9 Sowa-Staszczak A, Pach D, Mikolajczak R, et al. Glucagon-like peptide-1 receptor imaging with [Lys40 (Ahx-HYNIC- 99mTc/EDDA)NH2]-exendin-4 for the detection of insulinoma. Eur J Nucl Med Mol Imaging 2013;40:524-531.

10 Boerman OC, Gotthardt M. 18F-Labelled exendin to image GLP-1 receptor-expressing tissues: from niche to 
blockbuster? Eur J Nucl Med Mol Imaging 2012;39: 461-462.

11 Drucker DJ. Incretin action in the pancreas: potential promise, possible perils, and pathological pitfalls. Diabetes 2013;62:3316-3323.

12 Elashoff M, Matveyenko AV, Gier B, et al. Pancreatitis, pancreatic, and thyroid cancer with glucagon-like peptide1-based therapies. Gastroenterology 2011;141:150-156.

13 Nauck MA, Friedrich N. Do GLP-1-based therapies increase cancer risk? Diabetes Care 2013;36(Suppl 2): S245-S252.

14 Victoza $^{\circledR}$ (liraglutide injection) Human Relevance of Rodent Thyroid C-cell Tumors. http://www.fda.gov/ downloads/AdvisoryCommittees/Committees \% 20 MeetingMaterials/Drugs/EndocrinologicandMetabolicDrugsAdvisoryCommittee/UCM151129.pdf; Accessed 5 October 2010.

15 Bjerre Knudsen L, Madsen LW, Andersen S, et al. Glucagon-like peptide-1 receptor agonists activate rodent thyroid C-cells causing calcitonin release and C-cell proliferation. Endocrinology 2010;151:1473-1486.

16 Boess F, Bertinetti-Lapatki C, Zoffmann S, et al. Effect of GLP1R agonists taspoglutide and liraglutide on primary thyroid C-cells from rodent and man. J Mol Endocrinol 2013;50:325-336.

17 Butler AE, Campbell-Thompson M, Gurlo T, et al. Marked expansion of exocrine and endocrine pancreas with incretin therapy in humans with increased exocrine pancreas dysplasia and the potential for glucagon-producing neuroendocrine tumors. Diabetes 2013;62:2595-2604.

18 Butler PC, Elashoff M, Elashoff R, et al. A critical analysis of the clinical use of incretin-based therapies: are the GLP-1 therapies safe? Diabetes Care 2013;36: 2118-2125.

19 Gale EA. GLP-1-based therapies and the exocrine pancreas: more light, or just more heat? Diabetes 2012; 61:986-988.
20 Kahn SE. Incretin therapy and islet pathology: a time for caution. Diabetes 2013;62:2178-2180.

21 Waser B, Beetschen K, Pellegata NS, et al. Incretin receptors in non-neoplastic and neoplastic thyroid $\mathrm{C}$ cells in rodents and humans: relevance for incretinbased diabetes therapy. Neuroendocrinology 2011;94: 291-301.

22 Gier B, Butler PC, Lai CK, et al. Glucagon like peptide1 receptor expression in the human thyroid gland. J Clin Endocrinol Metab 2012;97:121-131.

23 Pyke C, Knudsen LB. The glucagon-like peptide-1 receptor-or not? Endocrinology 2013;154:4-8.

24 Pyke C, Heller RS, Kirk RK, et al. GLP-1 receptor localization in monkey and human tissue; novel distribution revealed with extensively validated monoclonal antibody. Endocrinology 2014;155:1280-1290.

25 Gier B, Matveyenko AV, Kirakossian D, et al. Chronic GLP-1 receptor activation by exendin-4 induces expansion of pancreatic duct glands in rats and accelerates formation of dysplastic lesions and chronic pancreatitis in the Kras(G12D) mouse model. Diabetes 2012;61:1250-1262.

26 Wild D, Caplin M, Christ E, et al. Glucagonlike peptide-1 vs. somatostatin receptor targeting in malignant insulinomas. J Nucl Med 2011;52: 1073-1078.

27 Körner M, Waser B, Schonbrunn A, et al. Somatostatin receptors subtype $2 \mathrm{~A}$ immunohistochemistry using a new monoclonal antibody selects tumors suitable for in vivo somatostatin receptor targeting. Am J Surg Pathol 2012;36:242-252.

28 Reubi JC, Schonbrunn A. Illuminating somatostatin analog action at neuroendocrine tumor receptors. Trends Pharmacol Sci 2013;34:676-688.

29 Nakamura T, Ito T, Uchida M, et al. PSCs and GLP-1R: occurrence in normal pancreas, acute/chronic pancreatitis and effect of their activation by a GLP-1R agonist. Lab Invest 2014;94:63-78. 